\title{
Prevalence and associated factors of antenatal depression among women attending antenatal care follow up at Michu Clinic in Ayder Comprehensive Specialized Hospital, Mekelle, Tigray, Ethiopia 2019.
}

Birhane Gebrehiwot Beyene ( $\square$ birhanegebrehiwot@gmail.com )

Mekelle University College of Health Sciences

Gebrewahd Bezabhy Gebremichael

Mekelle University College of Health Sciences

Abreha Tsegay Gebreselassie

Mekelle University College of Health Sciences

Primary research

Keywords: Antenatal depression, Antenatal follow-up, Mekelle, Michu clinic

Posted Date: April 14th, 2020

DOI: https://doi.org/10.21203/rs.3.rs-22003/v1

License: (c) (i) This work is licensed under a Creative Commons Attribution 4.0 International License.

Read Full License 


\section{Abstract}

Background Antenatal depression is a serious mental health problem that can negatively affect the lives of women. Depressive disorders are not only common and chronic among women throughout the world but also the principal source of disability. The scarce information and limited attention to the problem might aggravate the consequence of the problem and can limit the intervention to be taken. So the purpose of the study is to determine the prevalence and associated factors of antenatal depression among women. Methods An institutional based cross sectional study was conducted by systemic random sampling technique among 203 pregnant women following Antenatal care at Michu clinic in Ayder Comprehensive Specialized Hospital from March to June 2019. An interviewer administered Beck Depression Inventory (II) questionnaire was used to assess individual's depression condition after consent obtained from participants. Data was entered and analyzed by using statically package for social science version 22. Then bivariate regression with $p$-value $\leq 0.25$ was entered in to multivariate regression with $\mathrm{p}$-value

\section{Introduction}

Antenatal depression is a depression occurred during the period of pregnancy of mothers. Depression is the $4^{\text {th }}$ leading causes of disease burden and the largest causes of non- fatal burden accounting for almost $12 \%$ of all total years lived with disability worldwide(1).it is one of the most ancient and common diseases of the human race. Depressed patients are at least as heavily disabled as patients affected by other chronic diseases such as hypertension, rheumatoid arthritis and diabetes (2).

Depression is the most prevalence psychiatric disorder during pregnancy. Almost one woman out of four was experience depression at some point in her life, most commonly during the childbearing years(3) . Depressive disorders are not only common and chronic among women throughout the world but also the principal source of disability (1-3).

Antenatal depression often precedes postnatal depression (4) and causes great suffering to the women and her family(3). On top of that, untreated depression is associated with higher rates of morbidity and mortality. Similarly, discontinuation of antidepressant drug therapy in women with medication responsive illness carries a high risk for relapse and suicide attempts (5). More worryingly, per-natal depression has been found to be linked with infant under nutrition in many low income countries(6).

Negatively and low caregiver responsiveness may contribute to high rates of insecure attachment found among infants of depressed mothers (7). Children of depressed mothers are also at risk for slower cognitive development (8), low activity, difficulty interacting with unfamiliar and adults and unresponsiveness (9). Biomedical consequences including an increased risk for breastfeeding problems (10), eating and sleep disturbance (11), and a reduced likelihood of receiving preventative health care (12) or daily vitamin supplementation (13). Depressed mood during pregnancy has also been associated with poor attendance at antenatal clinics, substance misuse, low birth weight, and preterm delivery $(7,8)$. 
Antenatal depression is defined as the occurrence of a depressive episode in women during pregnancy. Prenatal depression is a non- psychotic depressive episode ranging from mild to severe symptoms that occur while a woman is pregnant period $(14,15)$. The WHO ranked depression as a single largest contributor to global disability in 2015.Depression has been reported more common among female population group as compared to male population group (16).

Depression affects an estimated $10 \%$ to $20 \%$ of pregnant women worldwide. Traditionally, pregnancy was viewed as a time protective against developing depression; consequently, the existence and consequences of have received little attention in either obstetrical, psychiatric, family medical practice, or mental health services. Depression is characterized by feeling of low self-worth, loss of interest, feelings of regret, restlessness, loss of appetite, feelings of fatigue, and poor concentration. Prenatal depression is a non-psychotic depressive episode ranging from mild to severe symptoms that occur while a woman is pregnant or during postnatal period.

Depression is one of the top contributors of global burden of diseases, which affects around 322 million people worldwide and is the leading reason for suicide. WHO, Global Health Estimates of 2015 reported that 788,000 people died due to suicide for every person who dies of suicide, 20 additional people attempted suicide. Depressive disorders led to a global total of over 50 million Years Lived with Disability in 2015 throughout the world(1, 2).

The estimated prevalence of depression worldwide is increased by 18.4\% from 2005 to 2015 in the world(3).Depression in pregnancy may diminish one's capacity for self-care including inadequate nutrition, drug or alcohol abuse, and poor antenatal clinic attendance all of which may compromise a women's physical and mental health and may reduce optimal fetal monitoring or restrict the growth and development of the fetus although nearly $90 \%$ of the world's children live in low and middle income countries (3).

In Ethiopia, depression is the third leading cause of burden of diseases and is also predicted to become the second leading cause of the global disease burden by the year 2020 (4). Depression is an emotional or affective state where a person may feel sad, lonely, or miserable with a "lack of interest" in their usual pleasurable activities (17).

In conclusion enormous numbers of individuals are being affected with general depression and it is responsible for 850,000 deaths per year. Results showed that $15 \%$ of the population from high income countries to $11 \%$ for low income countries is suffering with this problem. Antenatal depression is one of the ever maternal mental health problems that can be categorized under general depression which affects $10-15 \%$ of women before delivery.

The major aim of this study was to determine the prevalence and associated factors of antenatal depression among women attending antenatal care follow up at Michu clinic in ACSH. 
Therefore, early identification of maternal depression and the associated factors are potentially an effective strategy for decreasing maternal mortality and morbidity related to antenatal depression so that early screening of antenatal depression would improve the ability to recognize this disorder and enhances care that ensures appropriate health outcomes.

The evidence from this study would assist policy makers and program planners to take action to reduce the mortality and morbidity of mothers would able to take appropriate measurement.

Additionally, this study would provide relevant information for health workers to assess the magnitude and associated factors of antenatal depression which leads them to provide intensive professionally based antenatal support, to remain alert for associated factors of antenatal depression and would implement psychosocial support during the antenatal period and at the last it would be as an initial for other researchers for additional investigation.

Worldwide depression is the $4^{\text {th }}$ leading of diseases burden and the largest causes of non-fatal burden accounting almost $12 \%$ of all years lived with disability worldwide(1). AD precedes post-natal depression(4). Most of the core maternal symptoms of prenatal depression such as sleep disturbance and fatigue are frequently attributed to normal response of motherhood, which lowers the detection of prenatal depression (18).

One of the main components of sustainable development goal is improving maternal health and the vitality of mental health is stated through the theme "no health without mental health." In developing countries, one in three to one in five pregnant and postpartum mothers have mental illness(14). To realize sustainable development goals, efforts must include procedures to avert and manage the issue of maternal mental health during pregnancy and following birth of a baby(15). Prenatal depression's even milder symptoms impose a considerable health, social, and economic impact on the woman, her family, and her country at large $(19,20)$.

\section{Prevalence of antenatal depression}

Epidemiological data suggests that $15 \%$ of women are depressed at any one time throughout the world(21). The prevalence of $A D$ varies across different countries. For instance, the prevalence of $A D$ ranges from 7 to $15 \%$ in high-income countries throughout the world (22). The prevalence of $A D$ is also twofold higher among women from low- and middle-income countries (20\%) as compared to women from high-income countries in the world $(10 \%),(15,18)$.

Some researchers suggest that mothers of young children may have high rate of depression than general population of women in the world (23). The prevalence of $A D$ ranges from 19 to $25 \%$ in low-and middleincome countries worldwide(24).

The prevalence of $A D$ in Asia among 543 pregnant women attending antenatal care with beck depression inventory was used to assess the individual's depression condition and the prevalence was 15\%-28\% (8- 
11). In Pakistan 28\%-57\% among 312 pregnant women attending ANC follow up at public health center with BDI (I) (12) and 35\%-50\% in Latin America among 234 pregnant mothers attending ANC follow up by $B D I(I),(13)$.

A cohort study of women attending a district hospital antenatal clinic in Goa a specific place in china with study participants of 453, and community based study from Tamil Nadu, India with a total pregnant women of 387 reported a prevalence of $23 \%$ and $19 \%$ respectively where BDI (I) was used to assess the individuals depression condition $(25,26)$.

Another community cohort study from Pakistan reported a prevalence of $28 \%$ (27). A meta-analysis shows a prevalence of $A D$ is also high ranging from $0.5 \%$ to $51 \%$ in Pakistan (10). The prevalence of maternal depression is estimated to 15\%-28\% in Africa among 256 pregnant mothers attending ANC by $B D I$ (II), (13) .

The prevalence of $A D$ in South Africa is as high as $30-50 \%$ in one cross sectional study conducted in rural area of South Africa among 500 pregnant women attending ANC follows up in public health center(13).

In Ethiopia very few published studies are their concerning AD. These published researches show the prevalence of depression among pregnant women generally ranging from $4.4 \%$ to $12 \%$ (28-30). The prevalence of antenatal depression is reported to be 31.2\% in Adama Hospital among 345 pregnant mothers attending ANC at public health center by using BDI II (31), 31.1 \% in Maichew among 209 women attending antenatal care of the total women attending ANC follow up out of the source population of 600 pregnant mothers in public health centers using beck depression inventory to assess individual's depression condition with a cutoff point greater or equals to 14 (32), 29.5\% in Sodo district of Gurage Zone among 254 pregnant mothers with BDII with a cutoff point greater or equals to 14 (33) .

24.9\%inAddis Ababa Public Health Centers among 542 pregnant mothers attending ANC follow up at public health center by using BDI I with a cutoff point greater or equals to 14 (34).23\% in Gondar University Hospital among 388 pregnant mothers attending ANC follow up at Gonder University Hospital with $B D I(35,36)$ and a recent study in Dubti hospital located $10 \mathrm{Km}$ from Samara which is the capital city of Afar Regional state with prevalence of $17.9 \%$ and the sample size was 363 among a total of 4560 women following antenatal care per one year and the research was conducted with Beck depression inventory II with a cutoff point > or equals to 17 to assess the individual's depression condition(37).

The objective of the current review was to present an over view on the magnitude and associated factors of perinatal depression in Ethiopia.

\section{Determinants of antenatal depression}

Different studies conducted so far in different area reported Risk factors can be mentioned like sociodemographic characteristics, social support, obstetrics factors, previous psychiatric history and substances use for depression among pregnant mothers such as being young age was associated with $A D$ in Rawalpindi, Pakistan (11), low income associated with AD in Jamaica (12), lower educational 
attainment and obstetric factors in Rawalpindi, Pakistan (11) history of depression (11-13), history of miscarriage and pregnancy termination (7), concomitant high anxiety in pregnancy (38), low self-esteem (27) and low social support $(37,39,40)$.

Women from a developing country like Ethiopia are usually exposed to risk factors for the development of $A D$ like poor socioeconomic status, unintended pregnancy, and gender-based violence and history of childhood sexual abuse in Ethiopia $(28,41)$.

Socio-demographic characteristics, Pregnancy planning, social support, previous psychiatric history, obstetric factors and marital conflict were significantly associated with AD, a cross sectional study conducted in Northern Ethiopia at Dubti Hospital (37).

Bivariable logistic regression analysis showed that maternal education, average family monthly income, history of complication in previous pregnancy, and previous history of depression were statistically associated with antenatal depression in Northern Ethiopia Dubti Hospital (37).

In multivariable logistic regression analysis marital conflict, pregnancy planning, and social support were found to be significantly associated with $A D$. Those women who had marital conflict were about six times more likely to have AD as compared to those who had no marital conflict (37). Women who had planned their current pregnancy were $96 \%$ less likely to have antenatal depression as compared to women who had no planned pregnancy compared to women who had low social support, women who had medium social support less likely to have antenatal depression (37).

\section{Sociodemographic characters tics of antenatal depression}

The incidence of $A D$ is affected by different contributing factors among these socio demographic characteristics is one of the leading factors for $A D$. This has been revealed by different studies.

Firstly, when we see age, Young mothers were found to be at increased risk of AD than mothers of older age in British(14) (35). In contrast, a cross sectional study which was conducted in Turkish women revealed that the prevalence of $A D$ was higher in older women than younger (14). Beside a study in China tells the absence of association between $A D$ and maternal age (5). But in Ethiopia it has been revealed by different studies that Young mothers were found to be at increased risk of $A D$ than mothers of older age(27) .

Secondly, there is also evidence on the difference in the incidence of AD between educated and noneducated mothers with the higher prevalence of $A D$ in uneducated in developed country like Harvard University(27). But this result is in opposite with other findings where educational status of the mother did not associate with AD in the Rural developing world (5). Another cross sectional study in Qatar tells women who are educated are more vulnerable for the problem (22). In Ethiopia specifically Northern part in Dubti hospital reveled that Non-educated women have higher prevalence than educated women in a cross sectional study(37). 
Thirdly, single mothers appear to have greater risk of $A D$ in one study in rural South Africa (21).But in Ethiopia majority of participants were married and the prevalence is higher in married than women who does not married in a cross sectional study in Northern Ethiopia particularly Dubti Hospital (37).

Fourthly women who are in low economic status are also at high risk for AD in one cross sectional study in Harvard University (27) and in South Africa(25). Another study conducted in middle and low income countries in North East Africa with a systemic review study showed similar finding that women who are in low economic status have higher prevalence $(15,22,37,39)$ and a study conducted in Ethiopia revealed similar finding that women with low income status were found to have higher prevalence of AD. Almost 90 percent of study participants had reported that they earn an average family monthly income of more than500 Ethiopian Birr (the minimum Ethiopian wage during that time and Young mothers were found to be at increased risk of $A D$ than mothers of older age(37).

Fifthly, a Socio cultural factor ritual is among the list of factor which contributed for the incidence of $A D$ in one cross sectional study in British (14) but there is no conducted result about socio cultural factor in Ethiopia.

Sixthly, In different researches it has been mentioned that mothers who are working are also affected with the problem a cohort study in South Africa $(25,39)$, comparatively mothers who are unemployed are more at risk to develop AD than employed in a cross sectional study in Ethiopia $(15,29)$.

Seventhly, in Ethiopia Three hundred forty-five (96.6\%) and 205 (57.4\%) women were married and had attended formal education, respectively.

\section{Social support}

This was evident in different studies. On the study in developed countries which was conducted in 20102011 on 285 women by BDI I who gave birth in the Department of Obstetrics, Gynecology and Gynecologic Oncology at the University Hospital in Bydgoszcz has been mentioned that the child birth without the presence of any relatives was mentioned as a factor for $A D$ but another study concluded that there was no association between $A D$ and lack of social support in Jamaica $(12,38,39)$.

The incidence of $A D$ Women who have poor husband support were found to be at increased risk of $A D$ in a cohort study in rural population in a developing country worldwide (5), But in one cross sectional study conducted in Northern Ethiopia reveled that marital problem was a contributing factor for maternal depression in which (27.2\%) had encountered a conflict with their husbands in the last 12 months preceding the study.

For instance, in Ethiopia at least one in five women reported intimate partner violence(42) and women having history of intimate partner violence are 3 to 5 times likely to develop $A D(19,20,43,44)$. Despite extensive variations in the prevalence and associated factors of $A D$ across different communities of Ethiopia, there is no pooled evidence regarding the overall prevalence and potential associated factors of perinatal depression. 
Social support loss and marital conflict had higher prevalence of AD than women who had no conflict with their husband and women who had no social support in a study conducted in Ethiopia(37) .

\section{History of substance use}

Substance use particularly alcohol or khat, are not uncommon before or during pregnancy. Multiple addictions are also common, in particular alcohol with tobacco and alcohol with cannabis. A research conducted in University Hospital in Bydgoszcz has been mentioned that women using substance like khat and alcohol are associated with $A D(27)$. On a systematic review of the prevalence of antenatal depression among Women with Substance use, an abuse history, or Chronic illness by including seventeen papers on patient health questionnaire 9 assessing depression between 3 and 36 weeks of antenatal period there were high rates of $A D$ among substance-using women of khat and alcohol and those with current or past experiences of abuse in Southwest Ethiopia $(39,45)$.

Again another study in Ethiopia revealed that Prevalence of major depression was $12.4 \%$ for past-year pregnant women, of these women's 35.4\% had nicotine dependence. Twenty-one (5.9\%) of the study participants had used alcohol at least once in the last 30 days but none of the participants had reported current khat chewing(37).

\section{Obstetric factors of antenatal depression}

A study conducted in Iran indicated that unwanted pregnancy is not a risk factor for $A D(40)$. A research done on risk factor of depression in rural area of Isfahan province, Iran prime-paresis women were at higher risk for antenatal depression compared with multipara, prime-gravidia, multigravida (29). In one cohort study conducted in Southwest Ethiopia $(26,29,39,46)$ More than three-fourth $(76.2 \%)$ of pregnant women were in either the second or third trimester during the time of the study. A national survey in Ethiopia conducted in 2013 showed an overall unplanned pregnancy rate of $24 \%$.

Due to the associated higher risk women are at increased risk of having obstetric complications such as preterm labor, preeclampsia, fetal growth restriction, abruption placenta, and associated fetal and maternal complications(18). Women having such problems are usually less likely to seek and get care for themselves as well as their child, which intern leads to pre-term birth, low birth weight, and growth restriction $(24,47-49)$.

Another research conducted in Northern Ethiopia specific place of Maichew, two hundred eighty-four (79.6\%)of the women had planned their current pregnancy, of 221 women who had a history of pregnancy, 55(24.9\%) had a history of complication during previous pregnancy among 388 the participants in the study.

\section{Previous psychiatric history}

PPD has been found to elevate the risk of $A D$. A research conducted in developed countries, for example in Brazil there was a cross sectional study on the assessment of prevalence and associated of previous 
psychiatric disorder with bio-social-demographic factors, family history of psychological disorders was mentioned as a contributing factor for $A D(17)$.

There are also other studies which tell that women with PPD found to be at increased risk of $A D$, a cohort study conducted in developing countries throughout the world (5).

There are plenty of studies which tell that women with previous history of depression found to be at increased risk of $A D$, a cohort study conducted on different part of Ethiopia(32, 37). In general the study revealed that women who had PPD especially depression had higher prevalence than women who had no previous psychiatry history and About 97 (27.2\%) of the study participants reported a previous history of depression (37).

\section{Conceptual framework (Fig. 1)}

\section{Methodology}

\section{Study area}

The study was conducted at Ayder Comprehensive Specialized Hospital Mekelle specifically at Michu clinic is the capital city of the Tigray Region and located at 783 kilometers to the north of Addis Ababa, the capital city of Ethiopia. Mekelle University, College of Health Sciences/Ayder Comprehensive Specialized Hospital commenced rendering its referral and non-referral services in 2008, 9 million populations in its catchment areas of the Tigray, Afar and South-eastern parts of the Amhara Regional States. It provides a broad range of medical services to both in and out patients of all age groups.

As such, the Hospital can be designated as the most advanced medical facility, by all accounts, in the Northern part of the country and that it stands as the second largest hospital in the nation with the total capacity of about 500 inpatient beds in all departments and other specialty units. From the 500 inpatient bed 18 beds are in psychiatry department use for any disorders like psychotic or depression etc.

The Hospital is also used as a teaching hospital and research center for the College of Health Sciences, Mekelle University Ayder Comprehensive Specialized Hospital, and College of Health Science has above 80 specialists, in various areas of medical specializations and fairly adequate numbers of all the other health professionals constituting the health care team. It has about 50 international relations, over 2,165 staff and about 4,000 students.

Currently the institution has 61 programs with 21 under graduate, 30 post graduates including 10 specialty and three PhD programs generally the study was be conducted in ACSH specific place of Michu clinic which is established 2 years ago from now and is specific center for antenatal care and for family planning and other related purposes.

The climate condition of this area is sunny and cloudy and we preferred this area to conduct this research basically based on feasibility and because we can easily access women who follow antenatal care other 
than other centers since there is adequate number of women who follow ANC compared to other health centers.

\section{Study design and period}

- A Cross sectional study was conducted from March to June 2019.

Population

\section{Study population}

- Women who had ANC follow up during the study period in Ayder Comprehensive Specialized Hospital specifically Michu clinic.

\section{Source population}

- All Women who were following ANC follow up at Ayder Comprehensive Specialized Hospital specifically in Michu clinic, Mekelle, Tigray, Ethiopia.

Eligible criteria

\section{Inclusion criteria}

- Women who were in ANC follow up in Ayder Comprehensive Specialized Hospital.

- Age greater than or equals to 18.

\section{Exclusion criteria}

- Women who were unable to hear and speak

- Women who were seriously sick.

Sample size determination

The minimum number of sample required for this study was determined by using Single population proportion formula considering the following assumptions

$N i=(\underline{Z a / 2})^{2} \underline{p} \underline{p}(\underline{1}-\underline{p})$

$D^{2}$

Where

$\mathrm{Ni}=$ minimum sample size required for the study

$Z=$ standard normal distribution $(Z=1.96)$ with confidence interval of $95 \%)$ 
D2 = margin of error (5\%)

$P=$ population proportion $=17.9 \%$ (37), We preferred this population proportion since we were studying the magnitude and associated factors and this study conducted in Dubti hospital showed the associated factors better than the other studies conducted before.

$N i=\underline{1.96 \times 1.96 \times}(\underline{0.179})[1-0.179]$

$0.05 \times 0.05$

$N i=\underline{3.84 \times 0.179 \times 0.821=}$

0.0025

$\mathrm{Ni}=226$

Then we used the correction formula since the target population is less than 10,000 that is the total number of women visiting antenatal care was 981.

$N F=$ Correction $=n /(1+n / N)$, from this the target population $(N) 981$ the total number of women attending antenatal care per a year.

$N f=226 /[1+(226 / 981)]$

$N F=184$ women included in our study among 981 women attending in the clinic.

Add $10 \%$ non-response rate then add $18.4=19$

$N F=184+19=203$

Then since we used systemic random sampling technique we arranged them based on their triage and was selected every $K$ units.

That is $K=N / n$,

Where $\quad n$-is the sampling women included in the study

$N$-is the target population/women following ANC during the data collection period

$K=981 / 203=4.8$, approximated to 4 , this is the $K$ interval.

Then we selected participant women every 4 interval of women for this the first women was selected by lottery method among women triage of first woman to 4 woman, the first woman selected and was the first mother of the triage and selected based on $(1,5,10 \ldots . .$.$) .$

Sampling procedure and techniques 
- We used a probability sampling technique (systemic random sampling) among 203 pregnant women who was following antenatal care at Michu clinic based on their triage order from the clinic during their appointment.

- We faced with non - voluntary, non-communicable, seriously sick and other situations which make fluctuation women; we jumped and took the next mother.

Variables of the study

Dependent variable

$\square$ Antenatal Depression

\section{Independent variables}

\Socio demographic characteristics like age, economic status, employment, educational status, religion, and residence.

\Social support loss like husband support loss, community support loss.

Q History of substance use like khat, alcohol, cigarette and others.

\Obstetric factors, like being multi-gravidas, prime-gravidia, prime-parasis, unplanned pregnancy and history of past obstetric factors.

$₫$ Previous psychiatric histories like depression and family history of depression

\section{Operational definition}

- Antenatal depression: a depression occurred during the pregnancy period.

According to Beck's Depression inventory II(50) form a score of 14 or more is considered having depressive symptoms and can be classified as follow,

- Minimal depression considered as the score of 0-13 of beck depression scale.

- Mild depression with a score of 14-19 of beck depression scale.

- Moderate depression with a score of 20-28.

- Severe depression with score of 29-63

- A score of greater or equals to 17 is a cutoff point to detect depression in the study conducted in Ethiopia specific place of Dubti Hospital, for BDI II(37).

- Antenatal care: a care in which health professionals give support and follow the pregnancy status of women until give birth.

- Gestation period: Development of the fetus from the first day of the last period until birth, 40 weeks.

- Multigravida: Woman who has had more than one pregnancy. 
- Multipara: Woman who has given birth to more than one viable child.

- Primeparasis: A woman pregnant with her first child.

- Primgravidia: A woman who is pregnant for the first time.

- Low income level: Women with monthly income of <500 ETB (37).

- Medium income level: Women with monthly income >500ETB(37).

- High income level: Women with monthly income of >1000 ETB (37).

- Substance user: women who uses at least one of the specified substances starting from being pregnant (37).

- Social support loss: individuals who score >=9, either moderate or strong on Oslo 3-items social support scale (51).

\section{Data collection tools}

- We used self-administered standard questionnaire composed of closed ended and some open ended questions.

- Beck depression scale (BDI) II was used to assess individual's depression status which contains 4point scale values of 0 up to 3 .

- (BDI) II is a standardized questionnaire for depression which contains 21 items basically of depression symptoms(50).

\section{Data collection procedures}

- The data collection instrument was pretested for accuracy of responses, language clarity, appropriateness of data collection tools, estimate the time required and the necessary amendments was consider based on the pretest.

- We pretested the questionnaire outside of Michu clinic; It was carried out two week proceeding to the actual data collection period in five percent of non -study participants of women in Mekelle hospital.

- Maintaining confidentiality of the participants throughout the whole process of data collection was also discussed and ascertained during this period.

- We also had appraised the data during the data analysis stage to verify the completeness of the collected.

\section{Data quality control}

- To ensure data quality data was collected only by the investigators.

- The English version of questionnaire was translated to local language (Amharic, Tigrigna) and back translation to English to maintain its consistency by language experts.

- Based on the finding from the pretest, the questioner was revised and adopted. 


\section{Data analysis procedure}

- First we checked for completeness and consistency.

- Data was coded in order to enter in to computer.

- We used descriptive statistics to determine the prevalence of antenatal depression

- AOR with $95 \% \mathrm{Cl}$ was used to measure the association between depression and associated factors and bivariate and multivariate were also used to assess the relationship between each independent variable and showed strong association if p-value < or equals to 0.05 .

- Data was Analyses by SPSS version 22 software package.

- Generally bivariate was used and for the result is less than 0.25 then we transferred to multivariate and for the result is equals or $<0.05$, there was strong association.

- For all statistical testes in this study, the significant level set at $p$-value equals or $<0.05$.

- Then data presented with graphs, percentage and frequency tables.

\section{Dissemination of results}

The result of this study will be disseminated or communicated to Mekelle University, the central library for documentation, all campus administrative office of Mekelle University, College of Health Science Department of Nursing, and Psychiatric Nursing Staff for approval. Regional health bureaus and other concerned bodies through reports and publication on an appropriate journal and for any concerned body.

\section{Results}

Totally 203 ANC following women requested to participate in a study out of which all of them (100\%) Participants responded fully to all the questions.

\section{Sociodemographic characteristics of pregnant women}

The mean age of respondents were 27.57(SD=3.951), the median age was 28 years (range; 18-34years), the modal age of participants were 30 years. Most of participants 176 (86.7\%) were Orthodox followers. Among the participants 150(73.9\%) were educated Diploma and above and majority of participant 99(99\%) were living in urban. most of participants 148(72.9\%) had monthly income greater than 1000 and $88(45.3 \%)$ were Government workers (Table 1).

\section{Social support among pregnant mothers}

From the 203 participants 108 (53.2\%) had 1-2 close persons during great difficulty and 79(38.9\%) got some interest and concern about what they did. 54(26.6\%) had difficulty of getting practical help from their neighbors whenever they need help from them (Table 1).

Based on Oslo's scale from 203 participant women 148(72.9\%) had social support who scored greater or equals to 9, whereas 55(17.1\%) of them had social support loss (Fig.2). 
History of substance use among pregnant

Among 203 participants 188(92.6\%) of them did not used substance during pregnancy on the other hand $15(7.4 \%)$ of the participants used substance after being pregnant out of $18(8.9 \%)$ ever used substance. Among substance users during pregnancy $15(7.4 \%$ ) of them used alcohol (Table 3).

\section{Obstetric factors among pregnant mothers}

170 women out of $203(83.7 \%)$ of them had married, 159(78.3\%) of them does not had pregnancy complication, 193(95.1) had history of ANC follow up, 171(84.2\%) had regular ANC follow up and 183(90.1\%) had planned pregnancy. $127(62.6 \%)$ were prim-gravidia and $81(39.9 \%)$ had no give birth (Table 4).

\section{Previous psychiatric history among pregnant women}

Among 203 participants only 2 of (1\%) only reports previous history of depression and other mental illness and only 7 out of 203(3.4\%) reports history of depression and other mental illness among relatives (Table 5).

\section{Antenatal depression}

From all respondents $64(31.5 \%$ with) had antenatal depression who scored $>=17$ from the $B D I$ (II) considered to have antenatal depression (Fig. 3).

\section{Beck Depression Inventory II responses among pregnant women}

$B D I$ (II) is composed of 21 questions which indicate how mothers felt in the past two weeks and each question scored from 0 to 3 .

From all respondents $127(62.6 \%)$ of them reported they didn't felt sad, 163(80.3\%) didn't discouraged about their future workout, 115(56.7) of them didn't felt like a failure 48(23.6) of them did not enjoy as much they enjoyed in the past, 117(57.6\%) of participants didn't feel particularly guilty, 143(70.4\%) didn't feel of being punished, 150(73.9\%) of them didn't criticize themselves more than the usual, 163(80.3\%) didn't have thought of killing themselves, 141 (69.5\%) of them didn't cry any more than the usual, $89(43.8 \%)$ of them had feeling of more restlessness/wound up than the usual, 118(58.1\%) of them had no problem of decision making problem, 97(47.8\%) of them had no loss of interest in daily living activities, 102(50.2\%) of them didn't feel that they were worthlessness, 80(39.14\%) had less energy than usual, $45(22.2 \%)$ of participants sleep a lot more than day, $118(58.1 \%)$ of the respondents were not irritable, 68(33.5\%) of them had somewhat less than the usual, 130(64.0\%) of the respondents concentrated well as ever, 110(54.2\% had get more tired/fatigue than the usual and 82(40.4\%) had less interest in sex (Table 6). 


\section{Bivariate and multivariate regression of $A D$}

\section{Bivariate regression}

Binary Logistic regression was performed to assess the association of each independent variable with the outcome variable (antenatal depression). The variables that showed a significant level $(p<0.25)$ and COR with $\mathrm{Cl}$ 95\% were added to multivariate regression model (Table 7).

\section{Multivariate regression}

$P$ value $<0.25$ of the statically analysis were entered into multinomial logistic and $p$ value $<0.05$ in multinomial logistic is strong relationship with antenatal depression such as middle income; history of antenatal follow up and educational status of pregnant women had significance (Table 8).

\section{Discussion}

The study indicated that the prevalence of Antenatal Depression is 31.5\% with 95\% Cl $(24.7,37.9)$ respondents were depressed during their Antenatal period. The prevalence of antenatal depression varies across different countries and current study indicating that its prevalence is increasing from time to time.

The prevalence of this study is higher when compared to high income countries throughout the world $7 \%-15 \%(22)$, in Ethiopia country wide ranges from 4.4\%-12\% (28, 30), in Goa China and Tamil Nadu in India $23 \%$ and $19 \%$ respectively $(25,26)$ and in Dubti $(17.9 \%)$ among 363 pregnant women with BDI (II) (52) this might be due to different questionnaire, sample size, economical status, cultural difference, women's response towards the standard questionnaire and living status of women difference.

But in some part it is similar with other findings like, middle and low income countries throughout the world 19\% to $25 \%(24)$ (45), in Latin America (35\%-50\%) among 234 participant women with BDI (I) (13) (14), in Asia among 544 women $15 \%$ to $28 \%(8,11)$,in Africa $15 \%-28 \%(25,26)$, and in South Africa (30\%-50\%) among 500 pregnant women(13).

This study is in line with a research conducted in Addis Ababa 24.9\% with sample size 542 and BDI (I) and cutoff point $>=14$ (34), in Gonder University Hospital 29\% with sample size 388 and BDI (I) (36) , in Adama hospital (31.2\%) among 345 pregnant women with BDI (II) (32) and inMaychew (31.1\%) among 363 pregnant women with BDI (I) (37).

In this study the middle monthly income level of pregnant women is associated with antenatal depression with AOR of $95 \% \mathrm{Cl} 0.1999(0.066,0.597)$ in which women who had middle income level had $80 \%$ less likely to develop antenatal depression when compared to high monthly income women and this result is similar with a research conducted in Harvard University(52), in South Africa (25), in North East Africa(39) and in Northern Ethiopia at Dubti Hospital (37) and this might be due to women with middle income had less stress than higher income women. 
The educational status of the participants in this study showed an association with antenatal depression in which high school students were associated when compared to illiterate women with AOR of $95 \% \mathrm{Cl}$ $6.755(1.761,25.908)$ that is women with high school level educational status had 6.8 times more risk for antenatal depression and this is similar with a study conducted In Qatar women who are educated had higher prevalence of antenatal depression (22). Butnone educated were highly associated in rural developing world(5), in Harvard University (52) and in Ethiopia Dubti Hospital (37) showed that higher prevalence in non-educated women. In this study the high school level students had strong association with antenatal depression and this might be due to becoming of busy with work, less time to meet with their family members and their husband due to shortage of time.

History of antenatal follow up in the past showed association with antenatal depression in this study that is women who had no antenatal follow up were associated with antenatal depression with AOR of $95 \% \mathrm{Cl}$ $0.038(0.04,0.341)$ in which they had $96.2 \%$ less likely to develop antenatal depression and this might be related to culture in which some women might consider antenatal follow up as a deviation from their culture.

\section{Conclusion}

Antenatal depression is a common mental health problem at the pregnancy period and its prevalence continues in a significant proportion. This study found that $31.5 \%$ of respondents had antenatal depression which is significant high value.

It also identifies the presumed risk factors like socio-demographic factors like monthly income and educational status and similarly, women who had no antenatal follow up in the past had association with antenatal depression.

\section{Abbreviations}

ACSH............................... Ayder Comprehensive Specialized Hospital

$A D$................................Antenatal Depression

ANC ..............................Antenatal Care

AOD................................Adjusted Odd Ratio

BDI (I) ................................Beck Depression Inventory I

BDI (II)...........................Beck Depression Inventory II

COR .....................................Crude Odd Ratio

Cl..................................... Confidence Interval 
$E T B$ Ethiopia Birr

$P P D$. Previous Psychiatric Disorder

$S D G$ Sustainable Development Goal

SPSS 22 Statistical Packages for Social Science Version 22

WHO. World Health Organization

\section{Recommendation}

1. Health care providers should give attention and performing regular $A D$ screening for those women who had antenatal follow up.

2. Government should enable women to work in collaboration to be self-sufficient and Financially stable.

3. Further research should be done on antenatal depression using different study design, set up and sample size in order to investigate future some of the risk factors that were found to be associated with antenatal depression.

\section{Declarations}

\section{Authors' contributions}

BG, a principal investigator, analyzed and interpreted the patient data regarding Antenatal Depression. GB and AT are major contributor in writing the manuscript. All authors read and approved the final manuscript.

\section{Acknowledgements}

Our genuine thanks go to Mekelle University College of Health Sciences Department of psychiatric Nursing for its provision of the chance to conduct this study. At last but not the least I would like to thank Ayder comprehensive specialized, Michu clinic staffs for the information given on maternal and child health units and data used for this research, data collectors, and participants without whom this thesis would not be realized.

\section{Research involving human participants, their data or biological material}

The study was approved by Mekelle University, Health Science office of Health Research Ethics Review Committee (HRERC) and certifies that the study was performed in accordance with the ethical standards.

\section{Informed consent}


All participants have individual rights that are not to be infringed. Individual participants in studies have, for example, the right to decide what happens to the (identifiable) personal data gathered, to what they have said during a study or an interview, as well as to any photograph that was taken.

\section{Funding}

Not applicable for this section but the assumption source of funding is Mekelle University, College of Health Science.

\section{Availability of data and materials}

Not applicable.

\section{Ethics approval and consent to participate}

Ethical clearance was obtained from Mekelle University of Ayder Comprehensive Special Hospital, School of Nursing Department of Psychiatry Nursing. We were clearly explaining the aims of the study for study participant and collect the information after obtaining verbal consent from each participant. Respondents were also informed that they can refuse or discontinue participation at any time. They want and they had informed that they can ask anything about the study. Information was recorded anonymously and confidentiality was assured throughout the study period.

\section{Consent for publication}

Consent of publication for this research is Mekelle University, College of health science, psychiatry department and participants.

\section{Competing interests}

We declare that we have no compete of interests.

\section{References}

1. Patel V, Rodrigues M, DeSouza N. Gender, poverty, and postnatal depression: a study of mothers in Goa, India. American journal of Psychiatry2002;159(1):43-7.

2. Sousa A, Scheffler RM, Nyoni J, Boerma T. A comprehensive health labour market framework for universal health coverage. Bulletin of the World Health Organization;91:892-4.

3. Rahman A, Iqbal Z, Bunn J, Lovel H, Harrington R. Impact of maternal depression on infant nutritional status and illness: a cohort study. Archives of general psychiatry2004;61(9):946-52.

4. Black MM, Baqui AH, Zaman K, McNary SW, Le K, Arifeen SE, et al. Depressive symptoms among rural Bangladeshi mothers: implications for infant development. Journal of Child Psychology and Psychiatry2007;48(8):764-72. 
5. Rahman A, lqbal Z, Harrington R. Life events, social support and depression in childbirth: perspectives from a rural community in the developing world. Psychological medicine2003;33(7):1161-7.

6. Patel $V$, Rahman A, Jacob $K$, Hughes M. Effect of maternal mental health on infant growth in low income countries: new evidence from South Asia. Bmj2004;328(7443):820-3.

7. Rahman A, Bunn J, Lovel H, Creed F. Maternal depression increases infant risk of diarrhoeal illness:â€"a cohort study. Archives of disease in childhood2007;92(1):24-8.

8. Leigh B, Milgrom J. Risk factors for antenatal depression, postnatal depression and parenting stress. BMC psychiatry2008;8(1):24.

9. Qiu C, Sanchez SE, Lam N, Garcia P, Williams MA. Associations of depression and depressive symptoms with preeclampsia: results from a Peruvian case-control study. BMC women's health2007;7(1):15.

10. Reardon DC. The Post-Abortion Review. Gen;69(4):428-34.

11. Rahman A, Creed F. Outcome of prenatal depression and risk factors associated with persistence in the first postnatal year: Prospective study from Rawalpindi, Pakistan. Journal of affective disorders2007;100(1-3):115-21.

12. Wissart J, Parshad 0, Kulkarni S. Prevalence of pre-and postpartum depression in Jamaican women. BMC Pregnancy and Childbirth2005;5(1):15.

13. Da Costa D, Larouche J, Dritsa M, Brender W. Psychosocial correlates of prepartum and postpartum depressed mood. Journal of affective disorders2000;59(1):31-40.

14. Evans J, Heron J, Francomb H, Oke S, Golding J. Cohort study of depressed mood during pregnancy and after childbirth. Bmj2001,323(7307):257-60.

15. Fisher J, Mello MCd, Patel V, Rahman A, Tran T, Holton S, et al. Prevalence and determinants of common perinatal mental disorders in women in low-and lower-middle-income countries: a systematic review. Bulletin of the World Health Organization;90:139-49.

16. Golding JM. Intimate partner violence as a risk factor for mental disorders: A meta-analysis. Journal of family violence1999;14(2):99-132.

17. Aktas S, Calik KY. Factors affecting depression during pregnancy and the correlation between social support and pregnancy depression. Iranian Red Crescent Medical Journal;17(9).

18. Ferrari A, Somerville A, Baxter A, Norman R, Patten S, Vos T, et al. Global variation in the prevalence and incidence of major depressive disorder: a systematic review of the epidemiological literature. Psychological medicine;43(3):471-81.

19. Surkan PJ, Kennedy CE, Hurley KM, Black MM. Maternal depression and early childhood growth in developing countries: systematic review and meta-analysis. Bulletin of the World Health Organization;89:607-15.

20. Rahman A, Bunn J, Lovel H, Creed F. Association between antenatal depression and low birthweight in a developing country. Acta Psychiatrica Scandinavica2007;115(6):481-6. 
21. Rochat TJ. Depression among pregnant women testing for HIV in rural South Africa: Stellenbosch: University of Stellenbosch.

22. Grote NK, Bridge JA, Gavin AR, Melville JL, lyengar S, Katon WJ. A meta-analysis of depression during pregnancy and the risk of preterm birth, low birth weight, and intrauterine growth restriction. Archives of general psychiatry;67(10):1012-24.

23. De Bruin GP, Swartz L, Tomlinson M, Cooper PJ, Molteno C. The factor structure of the Edinburgh Postnatal Depression scale in a South African peri-urban settlement. South African Journal of Psychology2004;34(1):113-21.

24. Alder J, Fink N, Bitzer J, HÃ Isli I, Holzgreve W. Depression and anxiety during pregnancy: a risk factor for obstetric, fetal and neonatal outcome? A critical review of the literature. The Journal of MaternalFetal \& Neonatal Medicine2007;20(3):189-209.

25. Lawrie T, Hofmeyr G, De Jager M, Berk M. Validation of the Edinburgh Postnatal Depression Scale on a cohort of South African women. South African Medical Journal1998;88(10):1340-4.

26. Dawson DA, Grant BF, Stinson FS. The AUDIT-C: screening for alcohol use disorders and risk drinking in the presence of other psychiatric disorders. Comprehensive psychiatry2005:46(6):405-16.

27. University CotDCaH. Maternal Depression can Undermine the Development of Young Children. 2009.

28. Hanlon C, Medhin G, Alem A, Tesfaye F, Lakew Z, Worku B, et al. Impact of antenatal common mental disorders upon perinatal outcomes in Ethiopia: the Pâ€खMaMiE populationâ€खbased cohort study. Tropical Medicine \& International Health2009;14(2):156-66.

29. Ross J, Hanlon C, Medhin G, Alem A, Tesfaye F, Worku B, et al. Perinatal mental distress and infant morbidity in Ethiopia: a cohort study. Archives of Disease in Childhood-Fetal and Neonatal Edition;96(1):F59-F64.

30. Servili C, Medhin G, Hanlon C, Tomlinson M, Worku B, Baheretibeb Y, et al. Maternal common mental disorders and infant development in Ethiopia: the P-MaMiE Birth Cohort. BMC Public Health;10(1):693.

31. Sahile MA, Segni MT, Awoke T, Bekele D. Prevalence and predictors of antenatal depressive symptoms among women attending Adama Hospital Antenatal Clinic, Adama, Ethiopia. Int J Nurs Midwifery;9(5):58-64.

32. Mossie TB, Sibhatu AK, Dargie A, Ayele AD. Prevalence of antenatal depressive symptoms and associated factors among pregnant women in Maichew, North Ethiopia: an institution based study. Ethiopian journal of health sciences;27(1):59-66.

33. Bitew T, Hanlon C, Kebede E, Medhin G, Fekadu A. Antenatal depressive symptoms and maternal health care utilisation: a population-based study of pregnant women in Ethiopia. BMC Pregnancy and Childbirth;16(1):301.

34. Biratu A, Haile D. Prevalence of antenatal depression and associated factors among pregnant women in Addis Ababa, Ethiopia: a cross-sectional study. Reproductive health;12(1):99.

35. Prince M, Patel V, Saxena S, Maj M, Maselko J, Phillips MR, et al. No health without mental health. The lancet2007;370(9590):859-77. 
36. Bisetegn TA, Mihretie G, Muche T. Prevalence and predictors of depression among pregnant women in debretabor town, northwest Ethiopia. PloS one;11(9).

37. Belay YA, Moges NA, Hiksa FF, Arado KK, Liben ML. Prevalence of antenatal depression and associated factors among pregnant women attending antenatal care at Dubti Hospital: a case of pastoralist region in Northeast Ethiopia. Depression research and treatment;2018.

38. Stewart DE, Robertson E, Dennis C-L, Grace SL, Wallington T. Postpartum depression: Literature review of risk factors and interventions. Toronto: University Health Network Womenâ€ ${ }^{\text {TM }}$ S Health Program for Toronto Public Health2003.

39. Cox JL, Holden JM, Sagovsky R. Detection of postnatal depression: development of the 10-item Edinburgh Postnatal Depression Scale. The British journal of psychiatry1987;150(6):782-6.

40. Murray D, Cox JL. Screening for depression during pregnancy with the Edinburgh Depression Scale (EDDS). Journal of reproductive and infant psychology1990;8(2):99-107.

41. Najman J, Andersen M, Bor W, O'Callaghan M, Williams G. Postnatal depressionâ€"myth and reality: maternal depression before and after the birth of a child. Social psychiatry and psychiatric epidemiology2000,35(1):19-27.

42. Horrigan TJ, Schroeder AV, Schaffer RM. The triad of substance abuse, violence, and depression are interrelated in pregnancy. Journal of substance abuse treatment2000;18(1):55-8.

43. Sanchez SE, Puente GC, Atencio G, Qiu C, Yanez D, Gelaye B, et al. Risk of spontaneous preterm birth in relation to maternal depressive, anxiety and stress symptoms. The Journal of reproductive medicine,58:25.

44. Wado YD, Afework MF, Hindin MJ. Effects of maternal pregnancy intention, depressive symptoms and social support on risk of low birth weight: a prospective study from southwestern Ethiopia. PloS one;9(5).

45. Jebena MG, Taha M, Nakajima M, Lemieux A, Lemessa F, Hoffman R, et al. Household food insecurity and mental distress among pregnant women in Southwestern Ethiopia: a cross sectional study design. BMC Pregnancy and Childbirth;15(1):250.

46. Gavin NI, Gaynes BN, Lohr KN, Meltzer-Brody S, Gartlehner G, Swinson T. Perinatal depression: a systematic review of prevalence and incidence. Obstetrics \& Gynecology2005;106(5):1071-83.

47. Miranda JJ, Patel V. Achieving the Millennium Development Goals: does mental health play a role? PLoS medicine2005;2(10).

48. Kapetanovic S, Dass-Brailsford P, Nora D, Talisman N. Mental health of HIV-seropositive women during pregnancy and postpartum period: a comprehensive literature review. AIDS and Behavior;18(6):1152-73.

49. Vesga-Lopez O, Blanco C, Keyes K, Olfson M, Grant BF, Hasin DS. Psychiatric disorders in pregnant and postpartum women in the United States. Archives of general psychiatry2008;65(7):805-15.

50. Razka U. Hubungan Harga Diri dan Dukungan Sosial dengan Depresi Pada Pasien Paska Stroke di Poliklinik Rumah Sakit Stroke Nasional Bukittinggi Tahun 2017: Universitas Andalas. 
51. Dalgard OS, Dowrick C, Lehtinen V, Vazquez-Barquero JL, Casey P, Wilkinson G, et al. Negative life events, social support and gender difference in depression. Social psychiatry and psychiatric epidemiology2006;41(6):444-51.

52. Child NSCotD, Policy NFoEC, Programs. Maternal depression can undermine the development of young children: Harvard University, Center on the Developing Child; 2009.

\section{Tables}

Table1, the sociodemographic characteristics of women attending ANC follow up at Michu clinic in ACSH, Mekelle Tigray Ethiopia 2019(N=203).

\begin{tabular}{|c|c|c|c|}
\hline Items & Characteristics & Frequency $(\mathrm{N}=203)$ & $\begin{array}{l}\text { Percentage in } \\
\%\end{array}$ \\
\hline Age & $\begin{array}{l}\text { Age }<20 \text { years } \\
\text { Age of } 20-24 \\
\text { Age of } 25-29 \\
\text { Age of } 30-34\end{array}$ & $\begin{array}{r}50 \\
82 \\
67 \\
4\end{array}$ & $\begin{array}{r}24.6 \\
40.4 \\
33.0 \\
2.0\end{array}$ \\
\hline Religion & $\begin{array}{l}\text { Orthodox } \\
\text { Muslims } \\
\text { Others }\end{array}$ & $\begin{array}{r}176 \\
21 \\
6\end{array}$ & $\begin{array}{r}86.7 \\
10.3 \\
3\end{array}$ \\
\hline Residence & $\begin{array}{l}\text { Urban } \\
\text { Rural }\end{array}$ & $\begin{array}{r}201 \\
2\end{array}$ & $\begin{array}{r}99 \\
1\end{array}$ \\
\hline Educational status & $\begin{array}{l}\text { Diploma and above } \\
\text { High school } \\
\text { Elementary } \\
\text { Illiterates }\end{array}$ & $\begin{array}{r}150 \\
30 \\
16 \\
7\end{array}$ & $\begin{array}{r}73.9 \\
14.8 \\
7.9 \\
3.4\end{array}$ \\
\hline Income & $\begin{array}{l}\text { Income }<500 \\
\text { Income of 500-100 } \\
\text { Income }>1000\end{array}$ & $\begin{array}{r}46 \\
15 \\
148\end{array}$ & $\begin{array}{r}19.7 \\
7.4 \\
72.9\end{array}$ \\
\hline Occupation & $\begin{array}{l}\text { Government employ } \\
\text { Non government worker } \\
\text { Has no work } \\
\text { Others }\end{array}$ & $\begin{array}{l}88 \\
70 \\
37 \\
8\end{array}$ & $\begin{array}{r}45.3 \\
34.5 \\
18.2 \\
3.9\end{array}$ \\
\hline
\end{tabular}

Table 2, social support status of women attending antenatal care follow up in Michu clinic in ACSH, Mekelle Tigray Ethiopia 2019(N=203). 


\begin{tabular}{|c|c|c|c|}
\hline Items & Characteristics & Frequency $(\mathrm{N}=203)$ & Percentages in $\%$ \\
\hline The number of close persons during great difficulty & $\begin{array}{l}=>5 \\
3-5 \\
1-2 \\
\text { Only one }\end{array}$ & $\begin{array}{r}30 \\
44 \\
108 \\
21\end{array}$ & $\begin{array}{l}14.8 \\
21.7 \\
53.2 \\
10.3\end{array}$ \\
\hline How much interest and concern do people show in what you do & $\begin{array}{l}\text { A lot } \\
\text { Some } \\
\text { Uncertain } \\
\text { Little } \\
\text { Very little }\end{array}$ & $\begin{array}{l}59 \\
79 \\
22 \\
31 \\
12\end{array}$ & $\begin{array}{r}29.1 \\
38.9 \\
10.8 \\
15.3 \\
5.9\end{array}$ \\
\hline How easy is it to get practical help from neighbors if you should need it & $\begin{array}{l}\text { Very easy } \\
\text { Easy } \\
\text { Possible } \\
\text { Difficult } \\
\text { Very difficult }\end{array}$ & $\begin{array}{l}67 \\
35 \\
11 \\
54 \\
36\end{array}$ & $\begin{array}{r}33 \\
17.2 \\
5.4 \\
26.6 \\
17.7\end{array}$ \\
\hline
\end{tabular}

Table 3, substance use among women attending antenatal care follow up in Michu clinic in ACSH, Mekelle Tigray Ethiopia 2019(N=203).

\begin{tabular}{|l|l|r|r|}
\hline Items & Characteristics & Frequency $(\mathrm{N}=203)$ & Percentages in \% \\
\hline Have you ever used any substance & Yes & 18 & 8.9 \\
& No & 185 & 91.1 \\
\hline Do you use substance after being pregnant & Yes & 15 & 7.4 \\
If yes which substance do you use & No & 188 & 92.6 \\
& Khat & 2 & 1 \\
& Alcohol & 15 & 7.4 \\
& Others & 0 & 0 \\
\hline
\end{tabular}

Table 4, obstetric factors among attending antenatal care follow up in Michu clinic in ACSH, Mekelle Tigray Ethiopia 2019(N=203). 


\begin{tabular}{|c|c|c|c|}
\hline Items & characteristics & Frequency $(\mathrm{N}=203)$ & Percentage in \% \\
\hline \multirow[t]{2}{*}{ Have you married } & Yes & 170 & 83.7 \\
\hline & No & 33 & 16.3 \\
\hline \multirow[t]{2}{*}{ History of previous pregnancy complication } & Yes & 44 & 21.7 \\
\hline & No & 159 & 78.3 \\
\hline \multirow[t]{2}{*}{ History of antenatal follow up } & Yes & 193 & 95.1 \\
\hline & No & 10 & 4.9 \\
\hline \multirow[t]{2}{*}{ Pattern of antenatal follow up } & Regular & 171 & 84.2 \\
\hline & Irregular & 32 & 15.8 \\
\hline \multirow[t]{2}{*}{ Pattern of current pregnancy } & Planned & 183 & 90.1 \\
\hline & Not planned & 20 & 9.9 \\
\hline \multirow[t]{2}{*}{ Number of pregnancy } & Primgravidia & 127 & 62.6 \\
\hline & Multigravida & 76 & 37.4 \\
\hline \multirow[t]{3}{*}{ Number of live births } & None & 81 & 39.9 \\
\hline & Primpara & 68 & 33.5 \\
\hline & multipara & 54 & 26.6 \\
\hline
\end{tabular}

Table 5, previous psychiatric history among women attending antenatal care follow up in Michu clinic in ACSH, Mekelle Tigray Ethiopia 2019(N=203).

\begin{tabular}{|l|l|r|r|}
\hline Items & Characteristics & $\begin{array}{l}\text { Frequency } \\
\text { Percentages in \% }\end{array}$ & N =203 \\
\hline Previous history of depression and other mental illness & Yes & 2 & 1.0 \\
& No & 201 & 99.0 \\
\hline History of depression and other mental illness among relatives & Yes & No & 3.4 \\
& No & 96.6 \\
\hline
\end{tabular}

Table 6, Beck Depression Inventory scale II score among women attending antenatal care follow up in Michu clinic in ACSH, Mekelle Tigray Ethiopia 2019(N=203). 


\begin{tabular}{|c|c|c|c|}
\hline Items & Characteristics & $\begin{array}{l}\text { Frequency } \\
N=203\end{array}$ & Percentage in \% \\
\hline \multirow[t]{4}{*}{ Sadness } & 0 , I do not feel sad & 127 & 62.6 \\
\hline & 1, I feel sad much of the time & 49 & 24.1 \\
\hline & 2, I am sad all of the time & 19 & 9.4 \\
\hline & 3 , I am so sad that I cannot stand it & 8 & 3.9 \\
\hline \multirow[t]{4}{*}{ Pessimism } & 0, I am not discouraged about my future work out & 163 & 80.3 \\
\hline & 1, I feel more discouraged about my future & 16 & 7.9 \\
\hline & 2, I don't expect things to & 0 & 0 \\
\hline & 3, I feel my future is hopeless & 24 & 11.8 \\
\hline \multirow[t]{4}{*}{ 3,Past failure } & 0, I don't feel like a failure & 115 & 56.7 \\
\hline & 1, I have failed more than I should have & 39 & 19.2 \\
\hline & 2, as I look back I see lots of failures & 45 & 22.2 \\
\hline & 3, I feel my future is hopeless and worse & 4 & 2.0 \\
\hline \multirow{4}{*}{ 4, Loss of pleasure } & 0, I get as much pleasure from things I enjoy & 121 & 59.6 \\
\hline & 1, I don't enjoy as much I enjoy & 48 & 23.6 \\
\hline & 2, I get very little pleasure from I enjoyed & 19 & 9.4 \\
\hline & 3, I can't get any pleasure from I enjoyed & 15 & 7.4 \\
\hline \multirow[t]{4}{*}{ 5, Guilty feeling } & 0, I don't feel particularly guilty & 117 & 57.6 \\
\hline & 1, I feel guilty over many things & 74 & 36.5 \\
\hline & 2, I feel quit guilty most of the time & 7 & 3.4 \\
\hline & 3 , I felt guilty all of the time & 5 & 2.5 \\
\hline \multirow[t]{4}{*}{ 6, Punishment feelings } & 0, I don't feel I am being punished & 143 & 70.4 \\
\hline & 1, I feel I may be punished & 36 & 17.7 \\
\hline & 2 , I expect to be punished & 10 & 4.9 \\
\hline & 3, I feel I am being punished & 14 & 6.9 \\
\hline \multirow[t]{4}{*}{ 7,Self-dislike } & 0 , I feel the same about myself all-time & 150 & 73.9 \\
\hline & 1, I have lost confidence in myself & 30 & 14.9 \\
\hline & 2, I am disappointed in myself & 6 & 3 \\
\hline & 3, I dislike myself & 17 & 8.4 \\
\hline \multirow[t]{4}{*}{ 8, Self- criticalness } & 0, I don't criticize myself more than usual & 156 & 76.8 \\
\hline & 1, I am more criticize of myself than usual & 22 & 10.8 \\
\hline & 2, I criticize myself than I used to & 7 & 3.4 \\
\hline & 3, I blame myself for every bad happens & 18 & 8.9 \\
\hline 9, Suicidal thought or wishes & 0, I don't have thought of killing & 163 & 80.3 \\
\hline
\end{tabular}




\begin{tabular}{|c|c|c|c|}
\hline & 1, I have thought but I don't carry out myself & 28 & 13.8 \\
\hline & 2, I would like to kill myself & 8 & 3.9 \\
\hline & 3, I would kill myself if I had chance & 4 & 2 \\
\hline \multirow[t]{4}{*}{ 10, Crying } & 0, I don't cry any more than I used to & 141 & 69.5 \\
\hline & 1, I cry more than I used to & 28 & 13.8 \\
\hline & 2, I cry over every little thing & 29 & 14.3 \\
\hline & 3, I feel like crying but I can't & 5 & 2.5 \\
\hline \multirow[t]{4}{*}{ 11, Agitation } & 0, I am no more restlessness/ wound up than usual & 79 & 38.9 \\
\hline & 1, I feel more restless/wound up than usual & 89 & 43.8 \\
\hline & 2, I am so restless and agitated & 23 & 11.3 \\
\hline & 3, I am so restless/wound than usual & 12 & 5.9 \\
\hline \multirow[t]{4}{*}{ 13, decision problem } & 0 , I have any trouble to made decision & 118 & 58.1 \\
\hline & 1, I have somewhat trouble to made decision & 51 & 25.1 \\
\hline & 2, I have much more problem to made decision & 21 & 10.3 \\
\hline & 3, I can't made decision at all & 13 & 6.4 \\
\hline \multirow[t]{4}{*}{12 , Loss of interest } & $0, \mathrm{I}$ have no loss of interest in activities/people & 97 & 47.8 \\
\hline & 1,I am less interested in activities/ people & 69 & 34.0 \\
\hline & 2 , I have lost most of my interest & 26 & 12.8 \\
\hline & 3,It is hard to get interested in anything & 11 & 5.4 \\
\hline \multirow[t]{4}{*}{ 14, Worthlessness } & 0, I don't feel I am worthless & 102 & 50.2 \\
\hline & 1, I don't consider myself as worthwhile & 75 & 36.9 \\
\hline & 2, I feel more worthless than others & 14 & 6.9 \\
\hline & 3, I feel utterly worthless & 12 & 5.9 \\
\hline \multirow[t]{4}{*}{ 15, Loss of energy } & 0, I have as much energy as ever & 59 & 29.1 \\
\hline & 1, I have less energy than usual & 80 & 39.4 \\
\hline & 2 , I don't have enough energy to do very much & 43 & 21.2 \\
\hline & 3, I don't have enough energy to do anything & 21 & 10.3 \\
\hline \multirow[t]{8}{*}{16, Change in sleep pattern } & 0, I have not experienced change in sleep pattern & 34 & 16.7 \\
\hline & 1a, I sleep somewhat more than usual & 44 & 21.7 \\
\hline & 2a, I sleep a lot more than day & 45 & 22.2 \\
\hline & 3a, I sleep most of the time & 21 & 10.3 \\
\hline & OR & & \\
\hline & 1b, I sleep somewhat less than usual & 24 & 11.8 \\
\hline & $2 \mathrm{~b}$, I sleep a lot less than usual & 23 & 11.3 \\
\hline & 3b, I wake up 1-2hrs early \& can't get back & 12 & 5.9 \\
\hline 17, Irritability & 0, I am no more irritable than usual & 118 & 58.1 \\
\hline
\end{tabular}




\begin{tabular}{|c|c|c|c|}
\hline & 1, I am more irritable than usual & 73 & 36.0 \\
\hline & 2, I am much more irritable than usual & 6 & 3.0 \\
\hline & 3, I am irritable all the time & 6 & 3.0 \\
\hline \multirow[t]{8}{*}{ 18, Change in appetite } & 0, I have not experienced in change in my appetite & 48 & 23.6 \\
\hline & 1a, my appetite is somewhat less than usual & 68 & 33.5 \\
\hline & 2a, my appetite is much less than usual & 60 & 29.6 \\
\hline & 3a,I have no appetite at all time & 13 & 6.4 \\
\hline & OR & & \\
\hline & $1 \mathrm{~b}$, my appetite is somewhat greater than usual & 2 & 1.0 \\
\hline & $2 \mathrm{~b}$, my appetite is much greater than usual & 8 & 3.9 \\
\hline & $3 \mathrm{~b}, \mathrm{I}$ crave food all the time & 4 & 2.0 \\
\hline \multirow[t]{4}{*}{ 19, Concentration difficulty } & 0 , I can concentrate as well as ever & 130 & 64.0 \\
\hline & 1, I can't concentrate as well as ever & 57 & 28.1 \\
\hline & 2 , it is hard to keep my mind on anything long time & 11 & 5.4 \\
\hline & 3, I can't concentrate on anything & 5 & 2.5 \\
\hline \multirow[t]{4}{*}{ 20,Tiredness/fatigue } & 0, I am no more tired/fatigued than usual & 41 & 20.2 \\
\hline & 1, I get more tired/fatigued than usual & 110 & 54.2 \\
\hline & 2, I am too tired/fatigued than usual & 34 & 16.7 \\
\hline & 3, I am tired to do most things/minor work & 18 & 8.9 \\
\hline \multirow[t]{4}{*}{ 21, Loss of interest in sex } & 0, I have no change in my sex & 57 & 28.1 \\
\hline & 1, I am less interested in my sex interest & 82 & 40.4 \\
\hline & 2, I am much less interested in my sex interest & 51 & 25.1 \\
\hline & 3, I have lost interest in sex completely & 13 & 13 \\
\hline
\end{tabular}

Table 7, Bivariate regression result of antenatal depression among women attending

Antenatal care follow up in Michu clinic in ACSH, Mekelle Tigray Ethiopia 2019(N=203). 


\begin{tabular}{|c|c|c|c|c|c|c|c|}
\hline \multirow{3}{*}{ tems } & \multirow{3}{*}{ Characteristics } & \multicolumn{4}{|c|}{ Cross tabulation } & \multirow{3}{*}{ COR with $95 \%$ CI } & \multirow{3}{*}{$\begin{array}{l}\mathrm{P} \\
\text { value }\end{array}$} \\
\hline & & \multicolumn{2}{|c|}{ Not depressed } & \multicolumn{2}{|l|}{ Depressed } & & \\
\hline & & $\begin{array}{l}\text { In } \\
\text { number }\end{array}$ & $\begin{array}{l}\text { In } \\
\text { percent }\end{array}$ & $\begin{array}{l}\text { In } \\
\text { number }\end{array}$ & $\begin{array}{l}\text { In } \\
\text { percent }\end{array}$ & & \\
\hline \multirow[t]{4}{*}{ Age category } & $<20$ & 37 & 26.6 & 13 & 20.3 & $0.396(0.233,0.673)$ & 0.01 \\
\hline & $20-24$ & 52 & 37.4 & 30 & 46.9 & $0.35(0.187,0.661)$ & 0.01 \\
\hline & $25-29$ & 48 & 34.5 & 19 & 29.7 & $0.577(0.368,0.904)$ & 0.16 \\
\hline & $30-34$ & 2 & 1.4 & 2 & 3.1 & 1 & \\
\hline \multirow[t]{3}{*}{ Religion } & Orthodox & 126 & 90.6 & 50 & 78.1 & 1 & \\
\hline & Muslim & 11 & 7.9 & 10 & 15.6 & $0.397(0.286,0.551)$ & 0.000 \\
\hline & Others & 2 & 1.4 & 4 & 6.3 & $0.909(0.386,2.141)$ & 0.000 \\
\hline \multirow[t]{2}{*}{ Residence } & Urban & 137 & 98.6 & 64 & 100 & 1 & 0.000 \\
\hline & Rural & 2 & 1.4 & 0 & 0 & $0.577(0.368,0.904)$ & \\
\hline \multirow[t]{4}{*}{ छducational status } & Diploma and above & 103 & 74.1 & 47 & 73.4 & 1 & \\
\hline & High school & 22 & 15.8 & 8 & 12.5 & $0.577(0.368,0.904)$ & 0.000 \\
\hline & Elementary & 7 & 73.3 & 9 & 14.1 & $0.577(0.368,0.904)$ & 0.014 \\
\hline & Illiterate & 7 & 10.8 & 0 & 0 & $1.286(0.479,3.452)$ & 0.618 \\
\hline \multirow[t]{3}{*}{ Monthly income } & $<500$ & 33 & 23.7 & 7 & 10.9 & $0.154(0.035,0.682)$ & 0.014 \\
\hline & $500-1000$ & 13 & 9.4 & 2 & 3.1 & $0.212(0.094,0.480)$ & 0.000 \\
\hline & $>1000$ & 93 & 66.9 & 55 & 85.9 & 1 & \\
\hline \multirow[t]{4}{*}{ Jccupation } & Government employ & 65 & 46.8 & 23 & 35.9 & 1 & \\
\hline & $\begin{array}{l}\text { Non government } \\
\text { worker }\end{array}$ & 40 & 28.8 & 30 & 46.9 & $0.354(0.220,0.569$ & 0.000 \\
\hline & Has no work & 30 & 21.6 & 7 & 10.9 & $0.750(0.467,1.204)$ & 0.234 \\
\hline & Others & 4 & 2.9 & 4 & 6.3 & $0.233(0.102,0.532)$ & 0.001 \\
\hline \multirow[t]{2}{*}{ 亏̇ocial support } & Has social support & 98 & 70.5 & 50 & 78.1 & 1 & \\
\hline & Support loss & 41 & & 14 & 21.9 & $0.510(0.363,0.717)$ & 0.000 \\
\hline \multirow[t]{2}{*}{ Đver used substance } & Yes & 11 & 7.9 & 7 & 10.9 & 1 & \\
\hline & No & 128 & 92.1 & 57 & 89.1 & $0.636(0.247,1.642)$ & 0.350 \\
\hline \multirow[t]{2}{*}{ Jubs use during pregnancy } & Yes & 11 & 7.9 & 4 & 6.3 & 1 & \\
\hline & No & 128 & 92.1 & 60 & 93.8 & $0.364(0.116,1.142)$ & 0.083 \\
\hline \multirow[t]{3}{*}{ Гype of substance } & Khat & 2 & 1.4 & 0 & 0 & 1 & \\
\hline & Alcohol & 11 & 7.9 & 4 & 6.3 & $0.476(0.350,0.648)$ & 0.000 \\
\hline & Others & 0 & 0 & 0 & 0 & 0 & \\
\hline \multirow[t]{2}{*}{ Marriage } & Yes & 116 & 83.5 & 54 & 84.4 & 1 & \\
\hline & No & 23 & 16.5 & 10 & 15.6 & $0.466(0.337,0.643)$ & 0.000 \\
\hline \multirow[t]{2}{*}{ ?regnancy complication } & Yes & 26 & 18.7 & 18 & 28.1 & 1 & \\
\hline & No & 113 & 81.3 & 46 & 71.9 & $\begin{array}{r}0.692(0.380 \\
1.263) \\
\end{array}$ & 0.230 \\
\hline \multirow[t]{2}{*}{ AX of ANC follow up } & Yes & 137 & 98.6 & 56 & 87.5 & 1 & \\
\hline & No & 2 & 1.4 & 8 & 12.5 & $\begin{array}{r}0.409(0.300 \\
0.558) \\
\end{array}$ & 0.000 \\
\hline \multirow[t]{2}{*}{ ?attern of ANC follow up } & Regular & 119 & 85.6 & 52 & 81.3 & 1 & \\
\hline & Irregular & 20 & 14.4 & 12 & 18.8 & $0.437(0.315,0.605)$ & 0.000 \\
\hline \multirow[t]{2}{*}{ ?attern of current pregnancy } & Planned & 129 & 92.8 & 54 & 84.4 & 1 & \\
\hline & Not planned & 10 & 7.2 & 10 & 15.6 & $0.419(0.305,0.575)$ & 0.00 \\
\hline
\end{tabular}




\begin{tabular}{|c|c|c|c|c|c|c|c|}
\hline \multirow{2}{*}{ No of pregnancy } & Primgravidia & 57 & 41.0 & 19 & 29.7 & 1 & \multirow{2}{*}{0.000} \\
\hline & Multigravida & 82 & 59.0 & 45 & 70.3 & $0.333(0.198,0.560)$ & \\
\hline \multirow{3}{*}{ No of live birth } & No & 60 & 43.2 & 21 & 32.8 & 1 & \\
\hline & Primpara & 49 & 35.3 & 19 & 29.7 & $0.350(0.213,0.575)$ & 0.000 \\
\hline & Multipara & 30 & 21.6 & 24 & 37.5 & $0.388(0.228,0.659)$ & 0.000 \\
\hline \multirow[t]{2}{*}{ HX of depression } & Yes & 2 & 1.4 & 0 & & 1 & \\
\hline & No & 137 & 98.6 & 64 & 100 & 0.000 & 0.000 \\
\hline \multirow{2}{*}{$\begin{array}{l}\mathrm{HX} \text { of depression among } \\
\text { elative }\end{array}$} & Yes & 7 & 5 & 0 & & 1 & \\
\hline & No & 132 & 95 & 64 & 100 & 0.000 & 0.999 \\
\hline
\end{tabular}

Table 8, Multivariate regression result of antenatal depression among women attending antenatal care follow up in Michu clinic in ACSH, Mekelle Tigray Ethiopia 2019(N=203).

\begin{tabular}{|c|c|c|c|c|}
\hline Item & Characteristics & COR & AOR & $P$ value \\
\hline \multirow[t]{2}{*}{ Income } & $500-1000$ & $0.212(0.094,0.480)$ & $0.199(0.066,0.597)$ & \multirow[b]{2}{*}{0.004} \\
\hline & $>1000$ & 1 & 1 & \\
\hline \multirow[t]{2}{*}{ Hx of ANC follow up } & Yes & 1 & 1 & \multirow[t]{2}{*}{0.003} \\
\hline & No & $0.409(0.300,0.558)$ & $0.038(0.04,0.341)$ & \\
\hline \multirow[t]{2}{*}{ Educational status } & High school & $0.577(0.368,0.904)$ & $6.755(1.761,25.908)$ & \multirow[t]{2}{*}{0.05} \\
\hline & Illiterates & 1 & 1 & \\
\hline
\end{tabular}

\section{Figures}




\subsection{CONCEPTUAL FRAMEWORK}

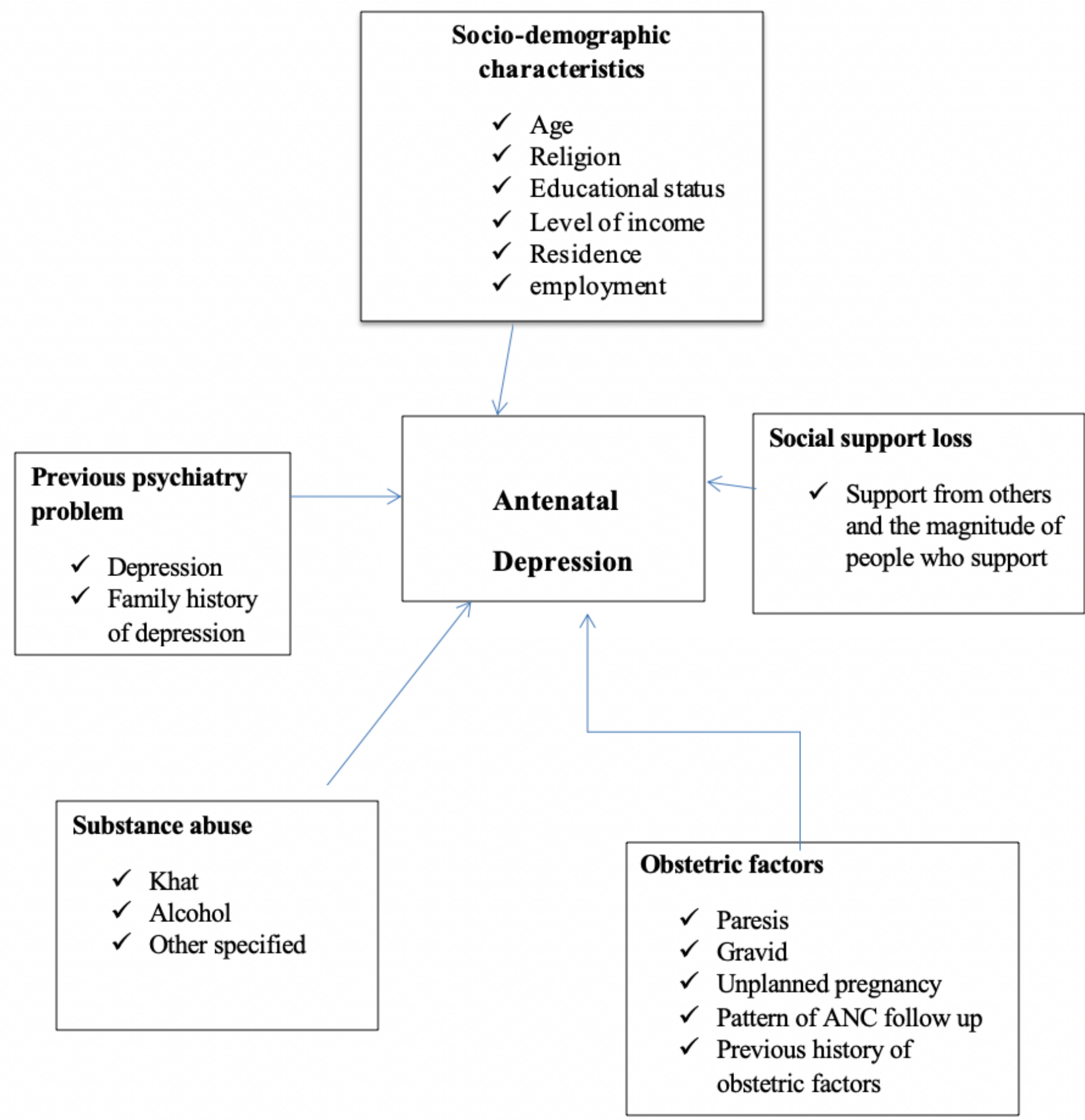

Figure 1

conceptual framework abstracted from the literature review $(11,30,37,39)$. 


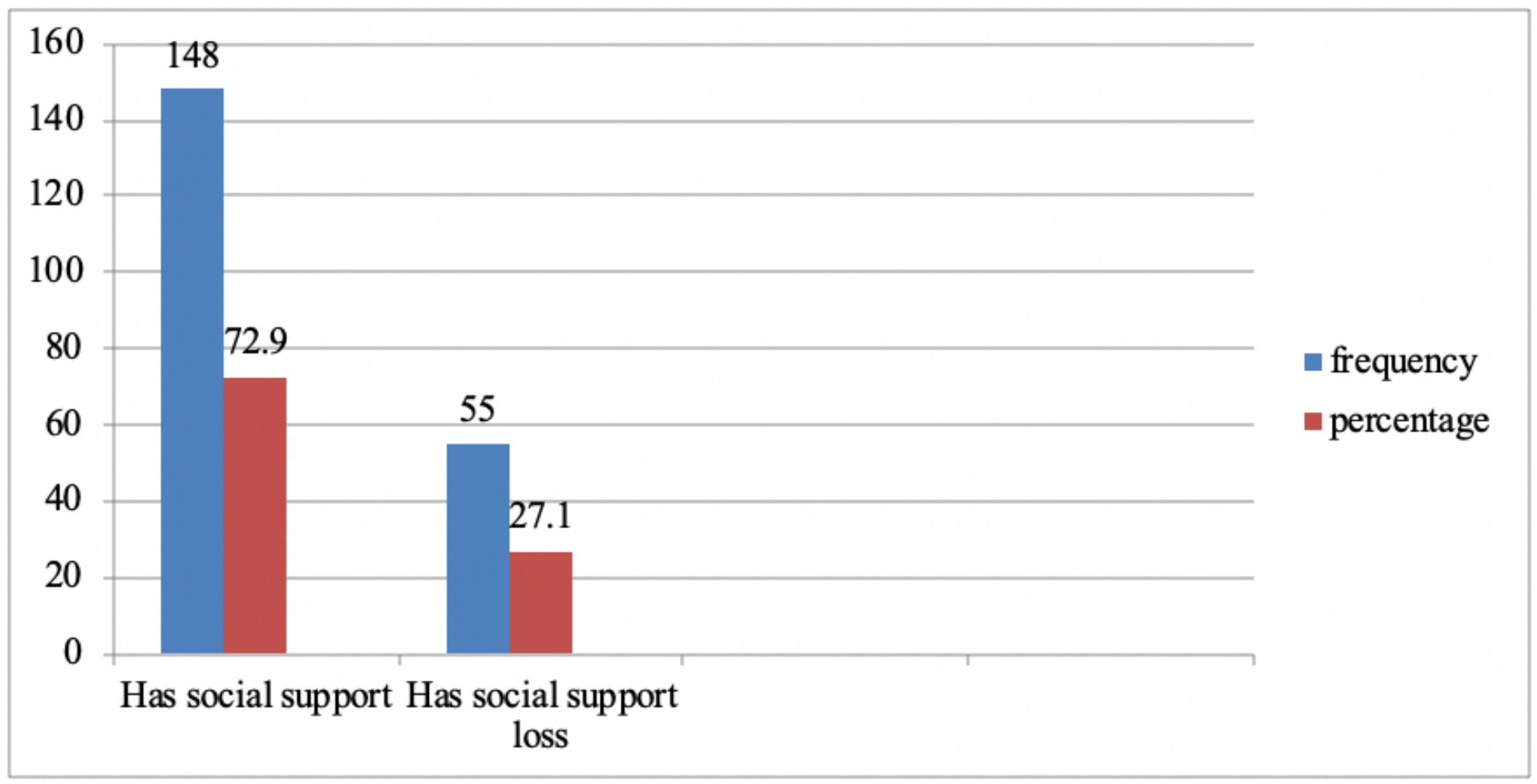

\section{Figure 2}

the social support status of women attending ANC follow up at Michu clinic in ACSH Mekelle Tigray Ethiopia 2019(N=203).

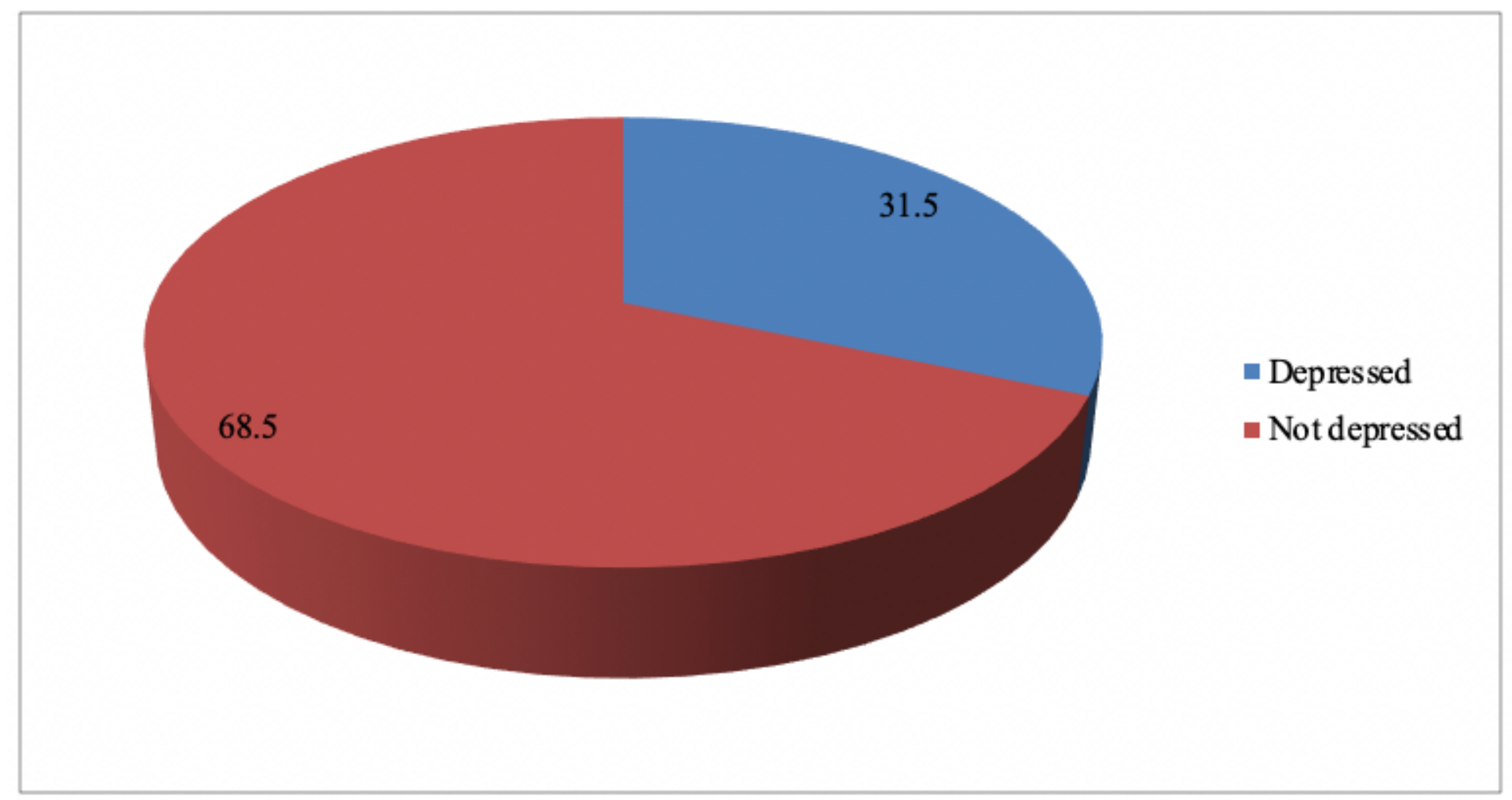

Figure 3 
prevalence of antenatal depressed women among women attending antenatal care follow up in Michu clinic in ACSH, Mekelle Tigray Ethiopia 2019(N=203) 